\title{
An investigation on research and development cost reduction and channel strategies in competing supply chains
}

Qinqin $\mathrm{Li}^{*}$ and Zhiying Liu

School of Management, University of Science and Technology of China, Hefei 230026, China

CHRON I C LE A B T T A C T

\author{
Article history: \\ Received September 202013 \\ Received in Revised Format \\ April 22014 \\ Accepted April 122014 \\ Available online \\ April 142014 \\ Keywords: \\ Supply chain competition \\ Cost reduction \\ Cournot competition \\ Game theory
}

\begin{abstract}
With the intensification of market competition, the competition form of firms is evolving from the competition among firms to the competition among supply chains. This paper considers a market with two competing supply chains consisting of one supplier and one manufacturer. The two supply chains compete on products' quantities and research and development (R\&D) level when the two manufacturers conduct technological innovation. This paper analyses the supply chain competition in three scenarios: two decentralized supply chains (DD), one decentralized supply chain and one centralized supply chain (DC) and two centralized supply chains (CC). The results indicate that the production quantity, the R\&D level and the total profit of the integrated supply chain in DC scenario are the largest, CC scenario comes second, those of the DD scenario come third and those of the decentralized supply chain in DC scenario are the smallest. CC strategy is the supply chain system's Nash equilibrium, which is good for the both supply chains, and there is no prisoner's dilemma.
\end{abstract}

\section{Introduction}

With the intensified competition among supply chains, the enterprises have to maintain continual technological innovation to improve quality of products, to reduce the costs of produce, as well as to develop new products, in an effort to increase competitive edge. For example, automobile makers conduct cost-reducing R\&D to lower prices of their products and to sell more cars. Most manufacturers who buy their products through suppliers have to decide whether to establish an integrated supply channel or a decentralized one. In this paper, we study this question in the presence of competing supply chains under Cournot competition.

Prior literature examined R\&D cooperation in different modes. An important stream of literature in duopoly competition, starting with D'Aspremont and Jacquemin (1988), focused on horizontal R\&D cooperation under Cournot competition and did not consider the effect of competition on channel coordination incentives, and cooperation was shown to be the optimal decision (Suzumura, 1992; Motta, 1992; Suetens, 2005). Suzumura (1992) examined the positive and normative effects of cooperative R\&D. Motta (1992) analyzed a partial equilibrium model with vertical product * Corresponding author.

E-mail: lqqzzu@mail.ustc.edu.cn (Q. Li)

(C) 2014 Growing Science Ltd. All rights reserved. doi: $10.5267 /$ j.ijiec.2014.4.004 
differentiation, Cournot competition and quality determined by R\&D expenses. Qiu (1997) compared Bertrand with Cournot equilibrium in a differentiated duopoly with R\&D competition and found that Cournot competition could induce more R\&D effort than Bertrand competition. Banker et al. (1998) examined whether equilibrium R\&D levels increase as competition intensified in three different competitive environment; namely asymmetric duopolistic competition, a symmetric duopoly and symmetric oligopolistic competition. Miyagiwa and Ohno (2002) extended the literature on cooperative R\&D in an oligopoly with spillovers by introducing uncertainty and focused on spillover of innovation. De Fraja and Silipo (2002) compared the subgame perfect equilibrium emerging in four regimes of R\&D competition among duopolists; namely full competition, coordination of research strategies, joint venture with cross licensing of patents, and full collusion in R\&D and the product market. Amir et al. (2003) focused on the performance of noncooperative and cooperative R\&D in product market competition and compared the equilibrium levels of $\mathrm{R} \& \mathrm{D}$, producer with consumer surplus, and social welfare. Suetens (2005) analyzed the relationship between technological spillovers and R\&D cooperation in a duopoly experiment based on the model of D'Aspremont and Jacquemin. Cellini and Lambertini (2009) investigated dynamic R\&D for process innovation in a Cournot duopoly where firms may either undertake independent ventures or form a cartel for cost-reducing R\&D investments. Besanko and $\mathrm{Wu}$ (2013) explored the trade-off between R\&D cooperation and competition with learning. The above literature on $R \& D$ cooperation focused mainly on horizontal $R \& D$ cooperation among firms who are competitors in the same product market. However, more and more firms with supply chain relationships are cooperating in $R \& D$ activities.

On the other hand, a parallel stream of literature, represented by McGuire and Staelin (1983), focused on the channel design problem in competing supply chains under Bertrand competition. This stream of literature started with McGuire and Staelin (1983), who investigated the effect of product substitutability on Nash equilibrium distribution structures in a duopoly where each manufacturer distributes its goods through a single exclusive retailer, which may be either a franchised outlet or a factory store. Gupta and Loulou (1998) analyzed a four-stage game with two manufacturers and two retailers, where the inter-channel contracts are linear and observable and manufacturers invest in process improvements to reduce their production costs. They found that the optimal channel structure decision depends on interactions between two parameters: the degree of substitutability between products cost reduction. They also reported that process innovation accents the profit difference between integrated and decentralized channels and makes the Prisoner's Dilemma situation worse in the choice of distribution channel structure. Banerjee and Lin (2001) examined the incentives of firms in vertical RJVs and analyzed two cost-sharing contracts, the proportional and the fixed fraction schemes. Ishii (2004) analyzed the effects of cooperative R\&D in two vertically related duopolies, which are two final-good manufacturers and two input suppliers, with horizontal and vertical spillovers. They compared the equilibrium outcomes under four vertical R\&D organization modes: noncooperative $R \& D$, vertical $R \& D$ cartels, vertical non-cooperative RJVs and vertical RJV cartels. Boyaci and Gallego (2004) modeled customer service competition of two competing supply chains, each consisting of one wholesaler and one retailer. They discussed the derivation of the equilibrium service strategies, resulting inventory policies, and profits for each scenario. They found coordination was a dominant strategy for both supply chains, but as in the prisoner's dilemma, both supply chains were often worse off under the coordinated scenario relative to the uncoordinated scenario and the consumers are the only guaranteed beneficiaries of coordination. Wu et al. (2007) addressed the problem of distribution channel design under demand uncertainty and focused on how demand uncertainty and production cost influence on the equilibrium distribution channel structure. Ha and Tong (2008) investigated contracting and information sharing in two competing supply chains. Xie et al. (2011) analyzed quality improvement in competing supply chains. Wu et al. (2012) addressed the decision of integration or decentralization from manufacturers' perspective in competing supply chains under demand uncertainty. They found the impact of demand uncertainty on integration/decentralization was complicated since it could favor either integration or decentralization, depending on how demand uncertainty was characterized. Manasakis et al. (2014) examined the 
downstream firms' incentives to invest in cost-reducing R\&D and to form a RJV, under two alternative structures of input supply: exclusive vertical relations and a single supplier.

Since the effect of the Cournot competition is not considered in competing supply chains with manufacturers' $R \& D$ reducing the cost, the usual conclusions from the above literature may be different from this study. This paper analyzes the channel decisions of two competing supply chains consisting of one supplier and one manufacturer. The two supply chains compete on products' quantities as well as non-price factor, R\&D level, when the two manufacturers conduct technological innovation. This paper analyses the supply chain members' production, R\&D level and profit in three scenarios: DD (two decentralized supply chains), DC (one decentralized supply chain and one centralized supply chain) and CC (two centralized supply chains).

This paper is organized as follows: the problem is described in section 2. Section 3 analyzes the competition equilibrium in DD, DC and CC and the results are discussed and compared in section 4. Finally, conclusions and implications for further research are given in section 5.

\section{Model Description}

Consider two competing supply chains both consisting of one supplier and one manufacturer. Each supply chain produces the same product as the other supply chain. The supply chain members have symmetry information. The manufacturer uses one unit of the intermediate product to produce one unit of final product. Similar to D'Aspremont and Jacquemin (1988), Hinloopen (1997), Banerjee and Lin (2001) and Ishii (2004), we assume that the demand for the final product is linear: $\mathrm{p}_{\mathrm{i}}=\mathrm{a}-\mathrm{q}_{\mathrm{i}}-\mathrm{q}_{\mathrm{j}}(i$,

$j=1,2$ and $i \neq j) . \mathrm{q}_{\mathrm{i}}$ is the demand for product $i, \mathrm{p}_{\mathrm{i}}$ is the price of product $i$. Assume the margin production cost of both manufacturers is c. To maintain analytical tractability, we don't consider the suppliers' margin production cost. The manufacturers both take on process innovation to reduce their cost by $x_{i}$ (R\&D level), we assume the innovation cost is $r x_{i}^{2} / 2$, which assures that the profit function is concave on $x$ (Gupta \& Loulou, 1998).

In this paper, the manufacturer dominates the whole supply chain in each supply chain, so the manufacturer is the Stackelberg leader. Our model can be described as a four-stage game. At stage one, each manufacturer decides between a centralized and a decentralized channel simultaneously and noncooperatively. At stage two, depending on the choices of the two manufacturers, there are three channel structures: DD, DC, CC, where DD represents that the two supply chains are decentralized, DC represents that one supply chain is decentralized and the other is centralized, CC represents that the two supply chain are centralized. Next, the competing supply chains make their decisions according the following order: (1) the manufacturers or supply chains determine the R\&D level at the same time; (2) the suppliers determines the wholesale price; (3)the manufacturers or supply chains take on Cournot quantity competition, and the customer buys the product. Next, we will analyze the equilibrium decisions of the three supply chain structures.

\section{Equilibrium decisions}

In this section, we establish and explore the subgame solution for each of the three supply chain structures from the stage one game: DD, DC and CC.

\subsection{DD case}

In the DD case, the two manufacturers simultaneously determine their R\&D level first, and then the two suppliers simultaneously set their wholesale prices. Finally, the two manufacturers take on Cournot quantity competition. We use backward induction to study the equilibrium decisions of the DD scenario.

The manufacturer's profit function is 
$\Pi_{m_{i}}^{D D}=q_{i}\left(a-q_{i}-q_{j}-w_{i}-c+x_{i}\right)-\frac{1}{2} r x_{i}^{2}$.

Solving the first order condition of production quantity yields,

$q_{i}=\frac{1}{3} a+\frac{1}{3} w_{j}-\frac{2}{3} w_{i}-\frac{1}{3} c+\frac{2}{3} x_{i}-\frac{1}{3} x_{j}$.

The suppliers' profit function is as follows,

$$
\prod_{s_{i}}=w_{i} q_{i}=w_{i}\left(\frac{1}{3} a+\frac{1}{3} w_{j}-\frac{2}{3} w_{i}-\frac{1}{3} c+\frac{2}{3} x_{i}-\frac{1}{3} x_{j}\right)
$$

Solving the first-order conditions of $\prod_{s_{i}}$ with respect to $w_{i}$ yields,

$$
w_{i}=\frac{1}{3} a-\frac{1}{3} c+\frac{7}{15} x_{i}-\frac{2}{15} x_{j} .
$$

Inserting Eq. (2) and Eq. (4) into Eq.(1) results the following,

$$
\prod_{m_{i}}=\left(\frac{2}{9} a-\frac{2}{9} c+\frac{14}{45} x_{i}-\frac{4}{45} x_{j}\right)^{2}-\frac{1}{2} r x_{i}^{2} \text {. }
$$

Solving the first order condition of $\prod_{m_{i}}$ with respect to $x_{i}$ yields,

$$
x_{i}=\frac{56(a-c)}{405 r-56}
$$

\subsection{DC case}

In the DC case, one supply chain is decentralized and the other supply chain is centralized. The decentralized manufacturer and the centralized supply chain simultaneously determine their R\&D level first, and then the decentralized supplier sets the wholesale price. Finally, the decentralized manufacturer and the centralized supply chain take on Cournot quantity competition. We use backward induction to study the equilibrium decisions of the DC scenario.

In the decentralized supply chain, the supplier's profit functions and the manufacturer's profit functions are as follows:

$$
\begin{aligned}
& \prod_{m_{1}}=q_{1}\left(a-q_{1}-q_{2}-w_{1}-c+x_{1}\right)-\frac{1}{2} r x_{1}^{2}, \\
& \prod_{s_{1}}=w_{1} q_{1} .
\end{aligned}
$$

The total profit function of the centralized supply chain is as follows,

$$
\prod_{s c_{2}}=q_{2}\left(a-q_{1}-q_{2}-c+x_{2}\right)-\frac{1}{2} r x_{2}^{2} .
$$

Solving the first order condition of production quantity yields,

$$
q_{1}=\frac{1}{3} a+\frac{2}{3} x_{1}-\frac{1}{3} c-\frac{1}{3} x_{2}-\frac{2}{3} w_{1}
$$


$q_{2}=\frac{1}{3} a-\frac{1}{3} x_{1}-\frac{1}{3} c+\frac{2}{3} x_{2}+\frac{1}{3} w_{1}$

For the decentralized supplier, the optimal wholesale price is as follows,

$$
w_{1}=\frac{1}{4} a+\frac{1}{2} x_{1}-\frac{1}{4} c-\frac{1}{4} x_{2}
$$

Inserting Eqs. (10)-(12) into Eq. (7) and Eq. (9) yields the following,

$$
\begin{aligned}
& \Pi_{m_{1}}=\left(\frac{1}{6} a+\frac{1}{3} x_{1}-\frac{1}{6} c-\frac{1}{6} x_{2}\right)^{2}-\frac{1}{2} r x_{1}^{2} \\
& \Pi_{s c_{2}}=\left(\frac{5}{12} a-\frac{1}{6} x_{1}-\frac{5}{12} c+\frac{7}{12} x_{2}\right)^{2}-\frac{1}{2} r x_{2}^{2}
\end{aligned}
$$

Therefore, we get the first order condition of the R\&D level

$$
\begin{aligned}
& x_{1}=\frac{4(a-c)(6 r-7)}{216 r^{2}-195 r+28} \\
& x_{2}=\frac{7(a-c)(15 r-4)}{216 r^{2}-195 r+28}
\end{aligned}
$$

Based on the equilibrium R\&D level, we derive the equilibrium production quantity, manufacturers' and suppliers' profit and the total profit of whole supply chain.

\subsection{CC case}

When the two supply chains both follow the centralized strategy, based on the collective rationality, the members of both supply chains choose the strategy to maximize the whole supply chains' profit. The two supply chains simultaneously determine their R\&D level first, and then they take on Cournot quantity competition. The competition between the two supply chains is the same as competition between duopoly. Then, the problem can be described as following functions

$$
\begin{aligned}
& \Pi_{s c_{1}}=q_{1}\left(a-q_{1}-q_{2}-c+x_{1}\right)-\frac{1}{2} r x_{1}^{2} \\
& \Pi_{s c_{2}}=q_{2}\left(a-q_{1}-q_{2}-c+x_{2}\right)-\frac{1}{2} r x_{2}^{2}
\end{aligned}
$$

Solving the first order condition of quantity, we have

$$
\begin{aligned}
& q_{1}=\frac{a-c+2 x_{1}-x_{2}}{3} \\
& q_{2}=\frac{a-c+2 x_{2}-x_{1}}{3}
\end{aligned}
$$

Inserting $q_{1}$ and $q_{2}$ into Eq. (17) and Eq. (18), we obtain

$$
\Pi_{s c_{1}}=\left(\frac{a-c+2 x_{1}-x_{2}}{3}\right)^{2}-\frac{1}{2} r x_{1}^{2}
$$


$\Pi_{s c_{2}}=\left(\frac{a-c+2 x_{2}-x_{1}}{3}\right)^{2}-\frac{1}{2} r x_{2}^{2}$

Deriving the first order condition with respect to $x_{1}$ and $x_{2}$ yields the following,

$x_{i}=\frac{4(a-c)}{9 r-4}$

Based on the equilibrium R\&D level, we derive the equilibrium production quantity and the total profit of both supply chains.

\section{Analysis of equilibrium results}

The equilibrium results, including production quantity, R\&D level, wholesale price, players' profit and the supply chains' total profit, are different in the three channel structures, shown in Table 1 . Next we compare the results.

\subsection{Comparison of equilibrium results}

(1) Production quantity

$q_{2}^{D C}>q_{i}^{C C}>q_{i}^{D D}>q_{1}^{D C}$

Proposition 1: In DC scenario, the supply chain which takes centralized supply chain structure generates the largest production quantity; In CC scenario, the two supply chains get the second production quantity; In DD scenario, the two supply chains get the third production quantity; In DC scenario, the supply chain which takes decentralized supply chain structure gets the least production quantity.

Table 1

Equilibrium solutions under three scenarios

\begin{tabular}{|c|c|c|c|}
\hline Variable & DD & $\mathrm{DC}$ & $\mathrm{CC}$ \\
\hline \multirow{2}{*}{ Quantity $q_{1}$} & $90 r(a-c)$ & $(a-c)\left(36 r^{2}-42 r\right)$ & $3 r(a-c)$ \\
\hline & $405 r-56$ & $216 r^{2}-195 r+28$ & $9 r-4$ \\
\hline \multirow{2}{*}{ Quantity $q_{2}$} & $90 r(a-c)$ & $(a-c)\left(90 r^{2}-24 r\right)$ & $3 r(a-c)$ \\
\hline & $405 r-56$ & $216 r^{2}-195 r+28$ & $9 r-4$ \\
\hline \multirow{2}{*}{ R\&D level $x_{1}$} & $56(a-c)$ & $4(a-c)(6 r-7)$ & $4(a-c)$ \\
\hline & $405 r-56$ & $216 r^{2}-195 r+28$ & $\overline{9 r-4}$ \\
\hline \multirow{2}{*}{ R\&D level $x_{2}$} & $56(a-c)$ & $7(a-c)(15 r-4)$ & $4(a-c)$ \\
\hline & $405 r-56$ & $216 r^{2}-195 r+28$ & $9 r-4$ \\
\hline Total profit $\pi_{1}$ & $\begin{array}{l}12150\left[\frac{r(a-c)}{405 r-56}\right]^{2}+ \\
{\left[\frac{90 r(a-c)}{405 r-56}\right]^{2}-\frac{1568 r(a-c)^{2}}{(405 r-56)^{2}}}\end{array}$ & $\begin{array}{l}{\left[\frac{(a-c)(6 r-7)}{216 r^{2}-195 r+28}\right]^{2} \cdot\left(36 r^{2}-8 r\right)+} \\
{\left[\frac{a-c}{216 r^{2}-195 r+28}\right]^{2} \cdot\left(36 r^{2}-8 r\right)\left(54 r^{2}-63 r\right)}\end{array}$ & {$\left[\frac{3 r(a-c)}{9 r-4}\right]^{2}-8 r\left[\frac{a-c}{9 r-4}\right]^{2}$} \\
\hline Total profit $\pi_{2}$ & $\begin{array}{l}12150\left[\frac{r(a-c)}{405 r-56}\right]^{2+} \\
{\left[\frac{90 r(a-c)}{405 r-56}\right]^{2}-\frac{1568 r(a-c)^{2}}{(405 r-56)^{2}}}\end{array}$ & $\left.\left[\frac{(a-c)\left(90 r^{2}-24 r\right)}{216 r^{2}-195 r+28}\right]^{2}-\frac{49 r}{2} \frac{(a-c)(15 r-4)}{216 r^{2}-195 r+28}\right]^{2}$ & {$\left[\frac{3 r(a-c)}{9 r-4}\right]^{2}-8 r\left[\frac{a-c}{9 r-4}\right]^{2}$} \\
\hline
\end{tabular}

(2) R\&D level

$$
x_{2}^{D C}>x_{i}^{C C}>x_{i}^{D D}>x_{1}^{D C}
$$


Proposition 2: The R\&D level of the supply chain choosing centralized supply chain structure in DC scenario is the largest, and the R\&D level of CC scenario is the second largest, and the R\&D level of DD scenario is the less, while the R\&D level of the supply chain choosing decentralized supply chain structure in DC scenario is the least.

(3) Total profit

$\pi_{2}^{D C}>\pi_{i}^{C C}>\pi_{m_{i}}^{D D}+\pi_{s_{i}}^{D D}>\pi_{m_{1}}^{D C}+\pi_{s_{1}}^{D C}$

Proposition 3: The total profit of the supply chain choosing centralized supply chain structure in DC scenario is the largest, and the total profit of CC scenario is the second largest, and the total profit of DD scenario is the less, while the total profit of the supply chain choosing decentralized supply chain structure in DC scenario is the least.

\subsection{Nash equilibrium analysis}

We get the Nash equilibrium of supply chain competition as Table 2 shows.

Table 2

Nash equilibrium of supply chain competition

\begin{tabular}{lll}
\hline & & SC2 \\
\hline SC1 & Decentralized & Centralized \\
\hline Decentralized & $\pi_{1}^{D D}, \pi_{2}^{D D}$ & $\pi_{1}^{D C}, \frac{\pi_{2}^{D C}}{\overline{C C}}$ \\
Centralized & $\pi_{1}^{C D}, \pi_{2}^{C D}$ & $\pi_{1}^{C C}, \pi_{2}^{C D}$ \\
\hline
\end{tabular}

As Table 2 shows, for supply chain 1 and 2, taking centralized supply chain structure is their strictly dominant strategy. The equilibrium solution for this supply chain system is CC strategy. Previous study shows that the coordination of supply chain will lead to prisoner's dilemma under price competition. This study shows that, under quantity competition, the supply chain system's equilibrium solution is CC strategy, which is good for both supply chains, and there is no prisoner's dilemma.

The management implications of this study are that CC strategy will be helpful to increase the profits of supply chain companies. In the real business, enterprises should cooperate more closely with other enterprises in the supply chain, share information and make decisions together. They should determine the production quantity according to the market demand so as to obtain benefit from the coordination of supply chain. Furthermore, they should not blindly expand the scale of the enterprise, to avoid the phenomenon of excess production capacity.

\section{Conclusion}

This paper considers the Cournot competition of two competing supply chains, in which each consists of one supplier and one manufacturer. The two manufacturers both conduct technological innovation. This paper analyses the supply chain members' production, technology strategy and profit in three scenarios: DD (two decentralized supply chains), DC (one decentralized supply chain and one centralized supply chain) and CC (two centralized supply chains). By means of game theory, we analyze the competition equilibrium and coordination strategy. The results indicate that the production, the R\&D level and the total profit of the supply chains in DC scenario are the largest, those of the CC scenario come second, those of the DD scenario come third and those of the decentralized supply chain in DC scenario are the smallest. The two supply chains could obtain a balanced solution in CC scenario, and the classical prisoner's dilemma will not appear in the supply chain system, and that the CC supply chain structure strategy is good for both supply chains. 


\section{Acknowledgement}

The authors would like to thank the anonymous referees for valuable suggestions.

\section{References}

Amir, R., Evstigneev, I., \& Wooders, J. (2003). Noncooperative versus cooperative R\&D with endogenous spillover rates. Games and Economic Behavior, 42 (2),183-207.

Banerjee, S., \& Lin, P. (2001). Vertical research joint ventures. International Journal of Industrial Organization, 19 (1), 285-302.

Banker, R.D., Khosla, I., \& Sinha, K.K. (1998). Quality and Competition. Management Science, 44 (9), 1179-1192.

Besanko, D., \& Wu, J. (2013). The impact of market structure and learning on the tradeoff between R\&D competition and cooperation. The Journal of Industrial Economics, 61 (1),166-201.

Boyaci, T., \& Gallego, G. (2004). Supply chain coordination in a market with customer service competition. Production and Operations Management, 13 (1),3-22.

Cellini, R., \& Lambertini, L. (2009). Dynamic R\&D with spillovers: Competition vs cooperation. Journal of Economic Dynamics and Control, 33 (3),568-582.

D'Aspremont, C., \& Jacquemin, A. (1988). Cooperative and noncooperative R \& D in duopoly with spillovers. The American Economic Review,1133-1137.

De Fraja, G., \& Silipo, D.B. (2002). Product market competition, R\&D, and welfare. Research in Economics, 56 (4),381-397.

Gupta, S., \& Loulou, R. (1998). Process innovation, product differentiation, and channel structure: Strategic incentives in a duopoly. Marketing Science, 17 (4),301-316.

Ha, A.Y., \& Tong, S. (2008). Contracting and information sharing under supply chain competition. Management Science, 54 (4),701-715.

Hinloopen, J. (1997). Subsidizing cooperative and noncooperative R\&D in duopoly with spillovers. Journal of Economics, 66 (2),151-175.

Ishii, A. (2004). Cooperative R\&D between vertically related firms with spillovers. International Journal of Industrial Organization, 22 (8),1213-1235.

Manasakis, C., Petrakis, E., \& Zikos, V. (2014). Downstream Research Joint Venture with upstream market power. Southern Economic Journal, 80 (3),782-802.

McGuire, T.W., \& Staelin, R. (1983). An industry equilibrium analysis of downstream vertical integration. Marketing Science, 2 (2),161-191.

Miyagiwa, K., \& Ohno, Y. (2002). Uncertainty, spillovers, and cooperative R\&D. International Journal of Industrial Organization, 20 (6),855-876.

Motta, M. (1992). Cooperative R\&D and vertical product differentiation. International Journal of Industrial Organization, 10 (4),643-661.

Qiu, L.D. (1997). On the dynamic efficiency of Bertrand and Cournot equilibria. Journal of Economic Theory, 75 (1),213-229.

Suetens, S. (2005). Cooperative and noncooperative R\&D in experimental duopoly markets. International Journal of Industrial Organization, 23 (1),63-82.

Suzumura, K. (1992). Cooperative and Noncooperative R\&D in an Oligopoly with Spillovers. The American Economic Review,1307-1320.

Wu, C., Du, H., \& Lu, X. (2012). Vertical integration in competing supply chains under additive stochastic demand. International Journal of Intercultural Information Management, 3 (1),82-106.

Wu, C., Petruzzi, N.C., \& Chhajed, D. (2007). Vertical Integration with Price-Setting Competitive Newsvendors. Decision Sciences, 38 (4),581-610.

Xie, G., Wang, S., \& Lai, K. (2011). Quality improvement in competing supply chains. International Journal of Production Economics, 134 (1),262-270. 